\title{
Remote sensing: the method of GIS application for monitoring the state of soils
}

\author{
Igor Grishin ${ }^{1, *}$ and Rena Timirgaleeva ${ }^{1}$ \\ ${ }^{1}$ Lomonosov Moscow State University, GSP-1, Leninskie Gory, 119991, Moscow, Russia
}

\begin{abstract}
Modern technologies of remote sensing of the Earth from space allow creating new information systems for observing and studying various processes occurring in biogeocenoses and agrocenoses. This is especially important in the case when it comes to the study of grape agrocenoses, since their most important elements are perennial plants and soils that provide a harvest. In this case, it is necessary to create special information technology for monitoring such objects. This will allow forming a series of observations that are uniform in time and space and provide the ability to conduct an analysis with a high degree of reliability in the future. The aim of this work is to develop methodological foundations for the formation of a system for remote diagnostics of soil fertility of grape agrocenoses in connection with the technology of cultivation and bioecological features of cultivated crops in solving problems of improving land use efficiency, as well as the creation of a mock-up of information system for remote monitoring of grape agrocenoses on their basis, aimed at solving tasks of predicting the condition of soils and vineyards, obtaining objective information about predicted fertility, solving problems of increasing land use efficiency, taking into account soil cultivation technologies and bioecological features of cultivated crops, abiotic and biotic factors.
\end{abstract}

\section{Introduction}

One of the most important tasks of the development of the economy of the Russian Federation and the regions is the development of its agricultural territories. The exchange of operational and reliable information in the field of managing the development of agricultural territories in the regions of the South of Russia is clearly insufficient and requires a search for new effective mechanisms for cooperation and coordination of business entities in this area.

At present, satellite-based observation technologies allow obtaining objective quantitative information about various objects and phenomena. This, in particular, allows creating new information technologies and systems for observing and studying various processes occurring in biogeocenoses and agrocenoses. At the same time, it should be noted that the study of various types of agrocenoses has its own specifics, which requires the creation of specialized information systems that allow for the receipt and analysis of

* Corresponding author: igugri@gmail.com 
information that is uniform in time and space. This is especially important in the case when it comes to the study of grape agrocenoses, since their most important elements are perennial plants and soils that provide a harvest. In this case, it is necessary to create special information technology for monitoring such objects. This will allow forming a series of observations that are uniform in time and space, and provide the ability to conduct an analysis with a high degree of reliability in the future. In this case, various characteristics of the studied objects which can be restored on the basis of remote observation data and be used to assess their status and development forecasts should be determined. These tasks can be effectively solved only in relation to certain types of research objects.

The aim of this project is to develop methodological foundations for the formation of a system for remote diagnostics of soil fertility of grape agrocenoses in connection with the technology of cultivation and bioecological features of cultivated crops in solving problems of improving land use efficiency, as well as the creation of a mock-up of information system for remote monitoring of grape agrocenoses on their basis aimed at solving tasks of predicting the condition of soils and vineyards, obtaining objective information on projected fertility, solving problems of improving land use efficiency taking into account soil cultivation technologies and bioecological features of cultivated crops, abiotic and biotic factors.

Ensuring and maintaining food security of the country is due to the sustainable development of the agricultural industry of the largest and most significant regions of Russia, which include the subjects of the Southern Federal District. From here, the most important tasks of such development can be set out: constant monitoring of the state of the region's lands in the broad sense (state of crops, monitoring of moisture, soil temperature, environmental monitoring), analysis and forecast of the development of changes in the state of the soil, development and implementation of a set of measures aimed at improving the condition of lands and their fertility.

The use of data received from remote sensing of the Earth's surface from space appeared as scientific and practical direction rather long ago - over fifty years ago, due to the significant scale of the country and individual regions. For example, the area of Krasnodar Territory is $75485 \mathrm{~km}^{2}$, which complicates the monitoring of agricultural land by traditional means. Therefore, the most promising monitoring methods are currently the methods of space monitoring (remote sensing) [1].

Considering the above mentioned, we note that today the study of ways to improve the management of the development of agricultural territories in the regions of southern Russia based on the introduction of geographic information technologies based on domestic results of space activities, integrating their results into the practice of resource-oriented development of agricultural regions of the south of Russia is an unsolved problem, which determines the need for this study [2, 3].

Agriculture is the most promising area of application of the Earth remote sensing data (ERS), including with the aim of increasing the stability of territories to agricultural exploitation. Crops are well shown in satellite images, they are not hidden by anything, single-tier, and well decrypted both in texture and in spectral characteristics [4].

It should be noted that the problem of ensuring the sustainable development of the agricultural sector of the region is complex, it must be solved on the basis of interpenetration (convergence) of space and information technologies, technologies for managing large business entities, as well as methods of systems theory and system analysis.

\subsection{Analysis of the Current State of Research}


A detailed analysis of a number of sources showed that the problems of space monitoring of territories based on the use of GIS had been developed in the works of Russian and foreign experts.

Intensive use of land often leads to the development of adverse processes (water and wind erosion, secondary salinization and waterlogging, soil pollution with industrial emissions and pesticides), which significantly degrades the properties of the soil cover. In this regard, there is a need to monitor indicators of the state of soils in order to assess, forecast and map them, as well as justify measures to increase soil fertility.

Soil monitoring includes systematic observations of the level of soil contamination, processes of chemical migration, and the dynamics of soil fertility in space and time. However, it cannot be limited only to the analysis of soil samples, since soil research is inseparable from the study of other components of the landscape, all the ways of accumulation of pollutants in both natural and anthropogenic complexes.

Describing the state of the soil cover in the territory under consideration, it should be noted that over the past half century, agricultural production in the vast territories was carried out due to irrigation capabilities, which decreased significantly after 2014, the area of irrigated agriculture decreased by 20 times, the land has been subject to erosion, salinization, and other adverse processes which occur in the regions of southern Russia and are caused by the closure of the North Crimean Canal, as well as a decrease in the annual flow to the Krasnodar and Stavropol Territories, the Rostov Region, as well as partially the republics of the North Caucasus.

Considering the large area of the territory, monitoring the state of soils and planning measures to preserve their fertility on this basis is impossible by traditional methods without the active use of remote sensing ones, primarily using methods of remote sensing of the Earth from space, as well as modern digital technologies, which is determined by the tasks of the national program "Digital Economy of the Russian Federation" [5].

A significant amount of work by domestic and foreign scientists and researchers has been devoted to the conservation and restoration of the fertility of agrocenoses. There are works devoted to remote assessment of soil conditions, a number of researchers used the results of remote sensing of the Earth from space to monitor soil fertility, soil mapping, as well as the condition of vineyards.

Land degradation negatively affects the food security of the world's population. According to some experts, at present, the share of disturbed lands is about $29 \%$ of our planet's land resources suitable for agricultural use [6].

The high ecological and economic importance of soils necessitates the creation of optimal mechanisms for regulating the intensity of their use. One of the primary tasks facing the country's soil scientists is the creation of the all-Russian soil-geographical database, which will serve as a state tool for regulating the use and protection of Russian soil resources. A computer inventory of soil information, its combination with existing digital maps, the use of modern GIS technologies will serve as the basis for the formation of soil monitoring, the development of a unified monitoring system, agrometeorological and environmental modeling of crop distribution at the regional and national levels [7].

Minimizing processing is the most important task of optimizing the crop cultivation system [8]. In Russia, its development has been carried out starting from the subsurface processing of T.S. Maltsev and soil protection system of A.I. Baraev before the development of regional combined systems of various degrees of minimization. In the framework of adaptive-landscape farming systems, a process of their differentiation has been outlined in relation to various soil-landscape conditions [9]. For the further development of the problem, a systematic generalization and expansion of scientific research in this area is required. 
Studies conducted in the countries of the Baltic region have shown that the economic value of losses resulting from land degradation is about 9 billion US dollars per year. Moreover, each dollar invested in the restoration of degraded soil ecosystems can bring about $\$ 3$ of social benefits in 6 years [10]. According to some researchers, the assessment and analysis of the soil degradation specifics should be based primarily on the study of the peculiarities of humus degradation in various variants of crop cultivation. It has been shown that after 2-3 years of tillage during the cultivation of corn, the content of organic carbon and nitrogen-containing compounds is significantly reduced, in general, the degradation of organic soil material occurs [11].

An integrated assessment of environmental sensitivity, sustainability and the dynamics of the qualitative characteristics of the soil is important in the strategy of planning and conducting agricultural work, especially in regions with a high level of land exploitation. Studies conducted in the region of the North Nile delta revealed a high level of risk of total soil degradation, especially in the southern part of the region, reduction of its quality and sustainability as a result of intensive agricultural use [12]. A method for finding the status indicator and assessing the quality of soil experiencing anthropogenic stress is suggested. The equation of the state function in general form is derived; a method for finding the parameters of this equation based on the interpretation of the experimental dose-response relationships is suggested. A scale of environmental assessment of soil quality has been introduced [13].

Based on the study of soils of different ages in different physiographic regions of the Crimean Peninsula, the main patterns of soil formation during the late Holocene (in the last 2800 years) have been revealed. According to the average rate of formation of the humus horizon, the main soil types on the territory of the Crimean Peninsula can be arranged in the following decreasing row: southern black soil and dark chestnut soils — brown mountain forest soils - brown gravel soils. During the late Holocene in newly formed soils, the process of humus accumulation was ahead of the process of increasing the thickness of the humus horizon. A period of a sharp decrease in the rates of the processes of soil profile formation and humus formation is observed at a soil age of 1100-1200 years. Possibilities for assessing the impact of climate on the soil-forming process according to meteorological data of the instrumental period have been established [14]. Due to the poor wetting of the upper layer of monolithic rock and zero starting fertility on the dense carbonate and shale rocks of the Crimea, a certain period of time is required to create a layer of weathered rocks under the influence of physical and chemical weathering (in our case, it is 10-12 cm), in which it will accumulate water that will stimulate chemical weathering. This will lead to the release of nutrients from the crystal lattice, which is characteristic of a more or less favorable environment for the development of microorganisms and plants. Only in the presence of such a layer will there be a possibility of realizing the biogenic cycle of soil formation, and the rate of soil formation will be maximum [15].

The methodological aspects and practical results of evaluating the energy of humus and the thermodynamic properties of soils of different ages in the Crimean Peninsula, which can be used as indicators of the potential ability of rocks to soil formation and self-healing of disturbed soils when developing land restoration strategies, have been considered. The energy values of humus in soils formed on various parent rocks have been determined [16].

The possibility of assessing the state of the soil cover by remote methods has been determined by the dependence of the soil color or reflectivity on the most important soil characteristics - moisture, humus content and properties, particle size distribution, carbonate content and free (non-silicate) iron. Currently, a system of indirect soil condition assessment has received some development, based on remote sensing data of the Earth, which can be used in mathematical modeling of soil processes [17, 18]. Peculiarities of soil development can be modeled using simulation models of soil-water-atmosphere-plant 
(SWAP), which are used in a computer program to simulate potential crops in different regions of the planet. Moreover, indicators of radiation and temperature conditions, standardized characteristics of crops under conditions of an adequate supply of water and nutrients and the absence of pests and diseases are used as basic elements. Italian researchers modeled the dynamics of the qualitative characteristics of the soil and showed a significant decrease on six types of soil in three variants of their degradation, taking into account the predicted climate change until 2100 [19].

There is a high need for remote sensing data for the operational management of soil and crop yields [20]. The spatial resolution and temporal frequency of remote sensing images have increased significantly. This allows evaluating soil indicators and plant characteristics in high spatial resolution by increasing the amount of data and increasing requirements for their processing. The temporal frequency of remote sensing images has also increased significantly. In recent decades, satellite methods and technologies have been increasingly used in solving problems of obtaining objective information about the use and condition of agricultural land. For these purposes, specialized information systems of various levels are actively developed and implemented. However, the use of remote methods and geological information technologies in the study of cultivated land from the point of view of a systematic approach, both in domestic and foreign scientific research, has not been sufficiently developed and requires further study of the possibilities of their effective use [21-23].

The use of space-based tools for Earth observation is one of the most effective and efficient methods for obtaining information on the state of agricultural systems, as evidenced by the many years of successful work of research teams in the field of development and implementation of methods for monitoring and assessing the state of plant objects based on satellite-based space observations. The consequence of this was significant progress in the development of methods and technologies for remote sensing of the Earth (ERS), which play a significant role in providing information for solving both fundamental and applied problems. The most significant progress in the development and application of remote sensing systems has occurred over the past decade. It was during this period that new generation systems appeared and began to be actively used, which made it possible to obtain not only qualitative, but quantitative information. The emergence of such systems has opened a new era of satellite remote sensing systems and allowed us to begin the creation of fundamentally new, highly automated technologies for working with remote sensing data, which ensure the organization of effective work with huge data arrays.

The development of Big Data and Data Science technologies, the emergence of superproductive computing systems allow you to continuously receive, analyze and use information on any region of our planet. This, in particular, allows us to analyze the temporal, including long-term, dynamics of various phenomena and processes. At the same time, in the early $2000 \mathrm{~s}$, various national and international programs focused on the creation of remote sensing spacecraft were actively developed, which led to a significant increase in both the number of space systems and potential capabilities. For example, from 1999 to 2009 , the number of spacecraft with multi-purpose scanners of the visible and infrared ranges for the study of land increased 1.5 times [24].

Currently, Spacecraft 78 is operating on orbit with equipment focused on studying the characteristics of the vegetation cover in the optical range [25]. A significant increase in the number of ERS spacecraft according to CEOS (Committee on Earth Observation Satellites) data will continue in the coming decades. The availability of satellite information in the last decade (including the possibility of obtaining it at a low cost or free of charge) has significantly expanded the possibility of its use in scientific research and has become one of the most significant factors influencing the development of remote sensing systems 
in the last decade. It was the availability of information that led to an almost explosive growth in developments in the use of satellite remote sensing systems of the Earth.

Thus, a generally accessible measuring instrument has appeared that has such unique properties (global observational zone, objectivity of information received, high repeatability, reproducibility, and the presence of archives of long-term continuous observations). This has led to the fact that in recent years, methods and technologies that allow obtaining objective data on the state of vegetation based on satellite information have developed quite rapidly. It should be especially noted that Russia has an active developmental activity in this field, which is not only not inferior to foreign analogues, but also surpass foreign analogues in matters related to the creation of automated data processing methods and distributed work systems with satellite information and the results of its processing.

Over the last decade, unique methods, algorithms, and technologies for working with satellite data have been created at the institutes of the Russian Academy of Sciences and Moscow State University, which have made it possible to solve a significant number of scientific problems, as well as create applied remote monitoring systems [26, 27].

It should be noted that throughout the entire history of the development of satellitebased earth observation systems, work has been actively conducted to create methods for remote assessment of vegetation, including agricultural. Methods with remote control of agricultural lands and crops have been created and are currently being actively developed. The work that focuses on the use of distance information to assess crop yields and various crops, as well as land productivity is underway. The details and directions of such works can be found, in particular, for example, in [29, 30].

It should be noted that in recent years, a significant number of works have been devoted to studying the features of the analysis of various types of vegetation using remote sensing data obtained in different spectral ranges. So, for example, in 1998-2008, the staff of the Institute of Agro-ecology of the NAAS of Ukraine formed a database of typical background optical characteristics of indicators of vegetation and soil cover, water bodies and wetlands, determined the relationship between the variability of optical characteristics and changes in various influence factors, substantiated the possibility of using the optical characteristics of indicators in assessing the ecological state of cultivated lands. Of course, it should be noted that the work on the analysis of the state of crops using remote sensing data has been carried out for more than 30 years, starting with the classic works [30] and continuing with more modern works [31] and others. At the same time, special attention is paid to the use of vegetation indices as indicators of the state of plants. To estimate the amount of photosynthetically active biomass, a normalized difference vegetation index (NDVI) has been developed [32], which is an indirect indicator of the moisture content of vegetation.

Considerable efforts have been spent on the creation of methods for mapping land cover, which are based on various methods for classifying satellite data, by researchers from various countries. To solve the problems of mapping land cover, various methods have been developed, such as controlled and uncontrolled classification - by different research groups over the past decades. The former include methods based on the decision tree [33], fuzzy classification [34, 35], decomposition of spectral mixtures [36].

The high cost of perennial vineyard crops, which are large water consumers, necessitates the creation of better tools to increase the efficiency of water use in order to remain economically viable and sustainable during periods of prolonged drought. To develop these tools, government, university, and industry partners in California are developing a multi-scale remote sensing-based simulation system for use in vineyards [37], infrared radiometry as a tool for early detection of water shortages was considered in [38]. The practical application of a multi-sensor UFV platform based on multispectral, thermal and RGB sensors with high resolution has been considered in the application to viticulture 
in [40]. Multi-time monitoring of vineyards using UFV-based RGB images was considered in [40], it was shown that the spectral indices of vegetation (VI) are good indicators of the water potential (stem) of the vine, helping to make irrigation decisions for commercial vineyards.

The authors [41, 42] showed that in karst cultivated lands, stony soils have a small moisture capacity; rational use of water for irrigation therefore plays an important role in management. Since the water holding capacity is heterogeneous, precision farming approaches will make it possible to make better management decisions. The study shows the applicability of hyper-spectral imaging to assess drought stress in vines, although temporal variability should be taken into account for early detection.

It should be noted that the publications lack comprehensive studies aimed both at identifying and substantiation of significant factors (indicators) affecting the fertility of grape agrocenoses, and development of methods for their assessment based on remote sensing of the Earth from space, building complex models for the development of such agrocenoses and the development of measures to improve or conserve soils under conditions similar to those in the south of Russia.

The suggested approaches are relevant for preserving the fertility of soils of grape agrocenoses in the regions of southern Russia, they are complex because they combine the methodology inherent in biology, information technology, physics and mathematics.

\subsection{Purpose of Research}

Purpose of research is the analysis and development of proposals for the creation of a space monitoring system for grape agrocenoses in the region of southern Russia, aimed at ensuring the sustainable development of viticulture.

\section{Methodology}

In the course of the study, both traditional general scientific and economical methods are applied, as well as natural science (mathematical) methods, methods of cybernetic control systems, as well as modeling and computer science, which should lead to a synergistic effect in this study and the achievement of new scientific results based on quantitative results of simulation along with traditional qualitative findings and results.

The methods of system analysis and management, economic and environmental safety, methods of analysis and synthesis, statistical and correlation analysis, tabular and graphical methods to display the results of analysis, methods of factor analysis are used. The normative and methodological foundation is based on the following normative documents: "Fundamentals of state policy in the field of using the results of space activities in the interests of modernizing the economy of the Russian Federation and developing its regions for the period up to 2030", "Plan of measures for 2015-2020 on the implementation of the Fundamentals of state policy in the field of using the results of space activities in the interests of modernizing the economy of the Russian Federation and the development of its regions for the period up to 2030", as well as the program "Digital Economy of the Russian Federation."

The peculiarity of this study is the reliance on the use of the domestic basic COSMOS geo-platform (developed by OAO Rekod Research and Manufacturing Complex) [3], on the basis of which modules of the monitoring system for environmental management and ecology of the information-analytical system of situational centers of the municipal and regional levels are created. The basis for the implementation of this project is the innovative and educational center for space services, which is being created at the Moscow State University and Kuban State Technological University, with access to space monitoring 
information of the Roskosmos State Corporation, as well as to the databases of the European Space Agency.

\section{Results and Discussion}

The space potential of Russia has been developing dynamically in recent years and includes the infrastructure for launching spacecraft, an orbital constellation, providing infrastructures and end-users, which include the governing bodies of the agricultural industry in the region. The relationship of these elements of the space potential of the country is shown in Fig. 1.

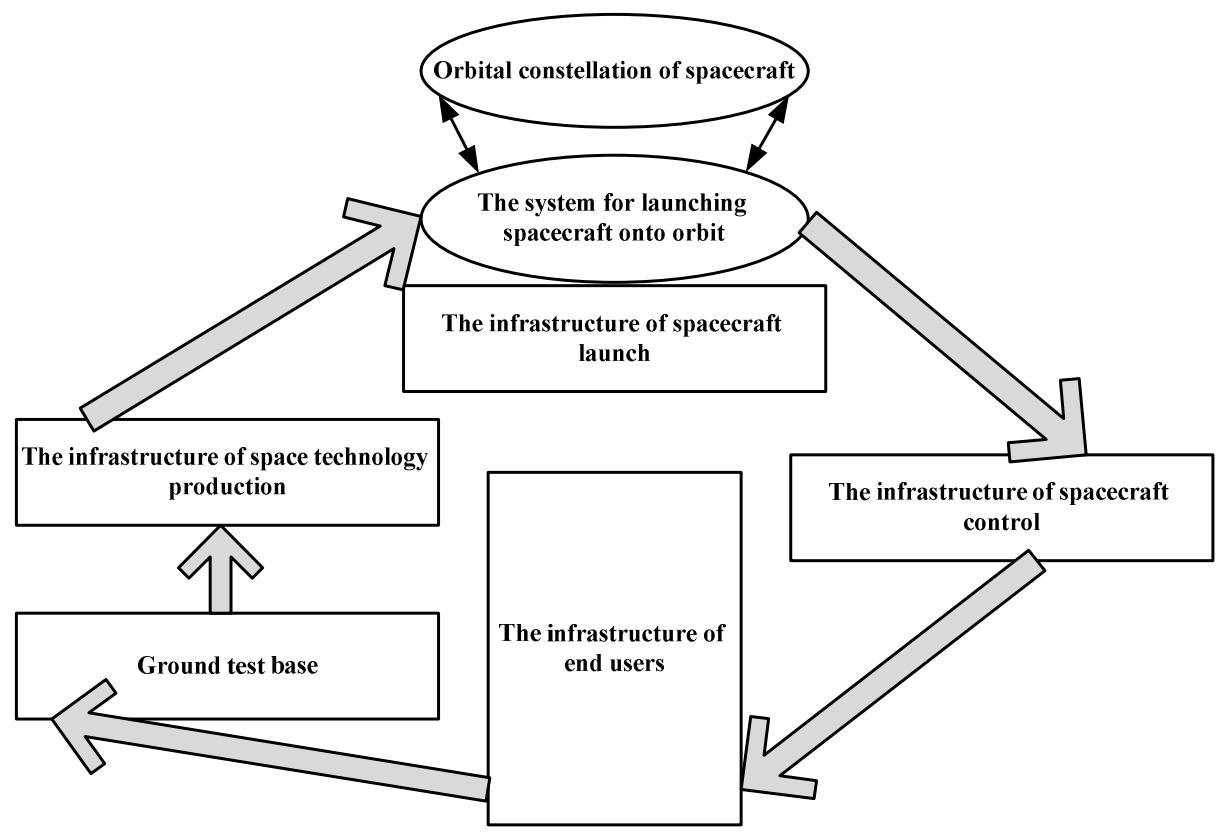

Fig. 1. The components of space potential.

Recent years in Russia are characterized by significant demand for modern space products and services. This is due to several factors: only space systems are capable of ensuring the continuous operation of global information fields - space monitoring, navigation, data transfer and control, as well as a number of others. The potential contribution of space systems to the development of the country's information infrastructure is shown in Fig. 2.

The analysis showed that technologies for the formation, maintenance and use of the total regional information resource (databases and knowledge), which has the following properties:

- integration with electronic cards and Global Navigation Satellite System data;

- structuring by sectors of the economy, territories and other objects of management;

- updating based on satellite images and other remote sensing systems;

- the provision of any end-users - both the public and managers at various levels in the form of visual, accessible and regulated services are most in demand with the constituent entities of the Russian Federation.

The results of long-term world economic statistics show that the use of space products and services reduces the costs of such activities as geodetic works, monitoring of objects, resources, phenomena, cartography by 2-3 times. The capabilities of space technologies are such that, when used together, they allow you to create multi-parameter remote monitoring 
systems that receive information at an arbitrarily large distance from the object itself, which provides the best conditions for organizing an economical, objective and reliable strategic and operational control.

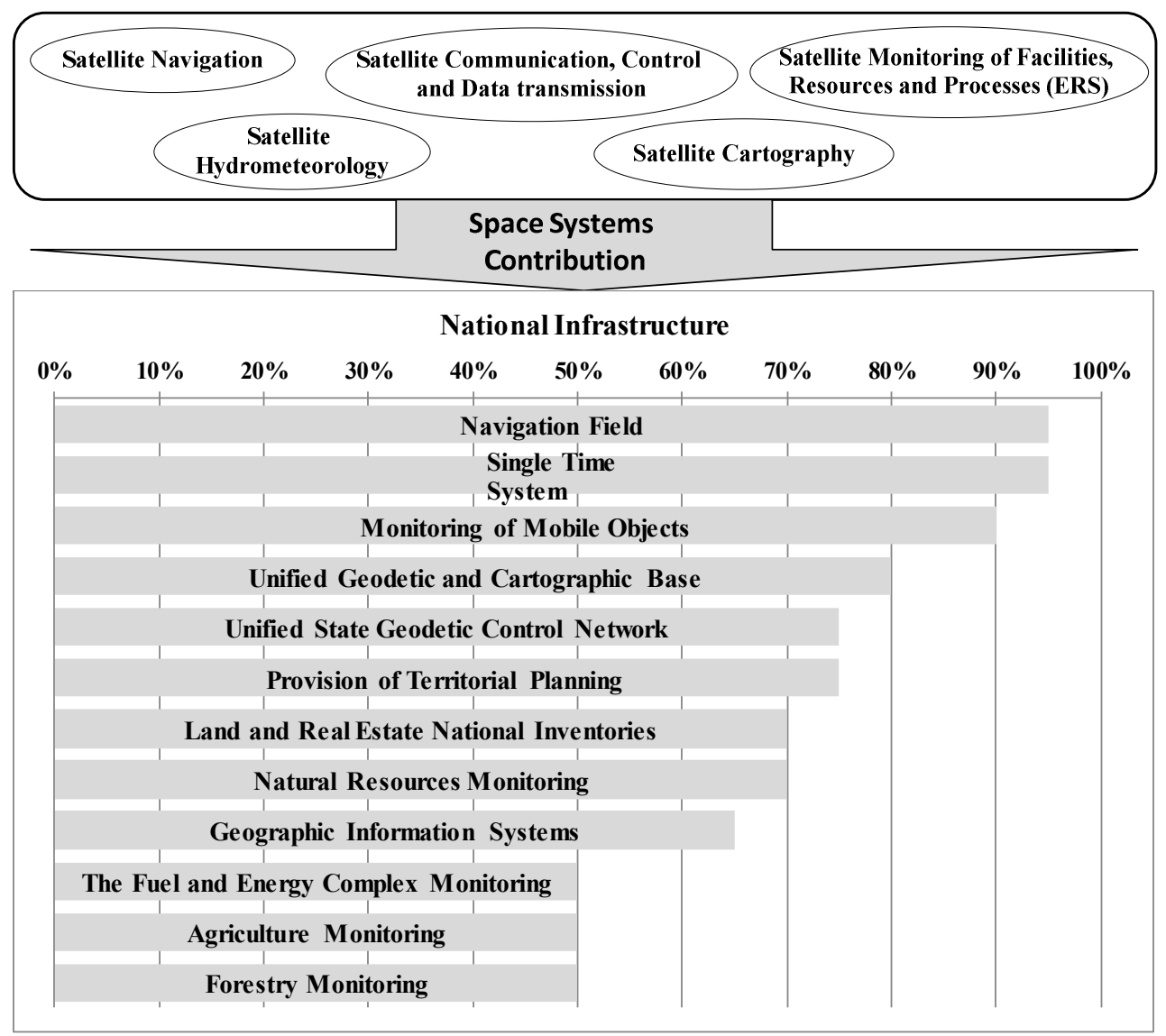

Fig. 2. The contribution of space systems to the development of the information infrastructure of the country

At present, domestic software (COSMOS platform) has already been created, which allows the development of monitoring and control systems that satisfy the above requirements. A system for linking all requirements in one software platform is shown in Fig.3.

It should be noted that it is advisable to place such a platform, as well as a platform for the region's digital economy, in the base of university data centers, providing space services centers of various levels with the necessary analytical and visual information.

The basic geographic information platform, as a rule, should have a structure (Fig. 4), which includes the following main components:

- system-wide software (software), including editors of bitmap and vector graphics, a graphical user interface for easy access to system tools, database management systems and analytical software; 


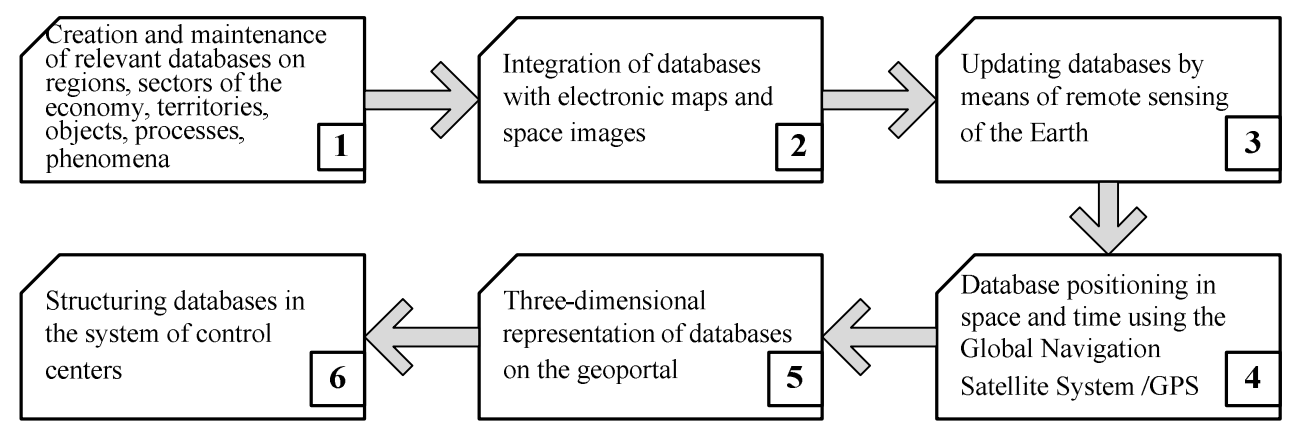

Fig. 3. The capabilities of the domestic geographical information platform.

- hardware (computers, data centers, telecommunication equipment, data storage systems, etc.);

- data (spatial data):

a) positional (geographical data) - the location of the object on the surface of the Earth;

b) non-positional (attributive) - descriptive, textual, photo, video;

- technology.

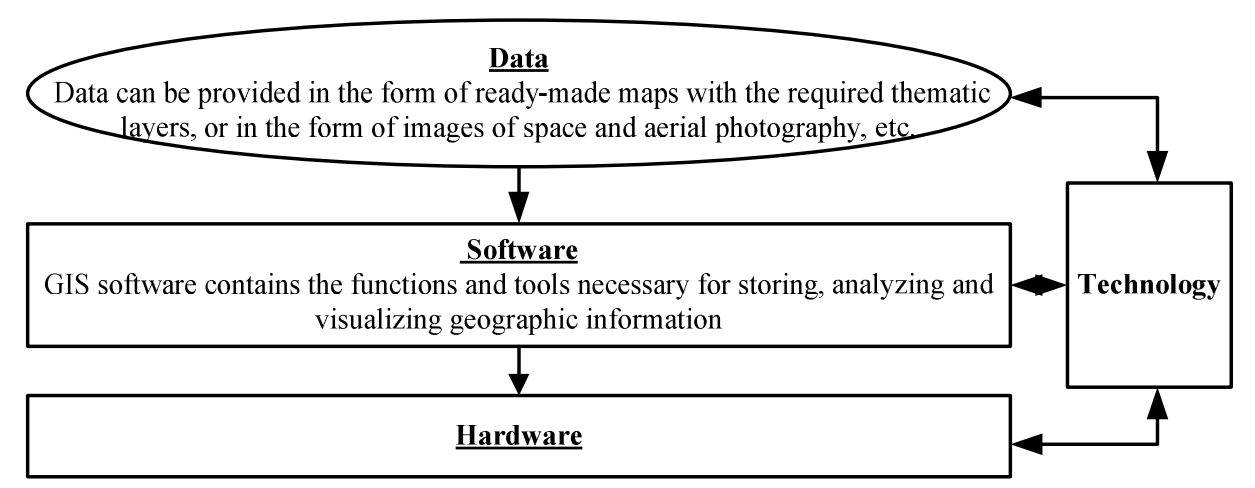

Fig. 4. The structure of the basic geographical information system platform.

The life cycle of processing and application of information received from the satellite can be represented in the form of a diagram in Fig. 5.

It should be noted that the processing and use of satellite data can be cyclical in nature and the processing of the same data in some blocks (Fig. 5) can occur repeatedly. Sometimes, it is necessary to introduce additional blocks to take into account the specifics of the processed information.

Let us consider the technologies necessary for integrated information and navigation support and monitoring of large agricultural territories using the example of a hardwaresoftware complex of the target agricultural monitoring system.

The target agricultural monitoring system is designed to provide information to the relevant executive authorities of a constituent entity of the Russian Federation and business entities on the inventory and accounting of agricultural land in the region, the state of agricultural lands and their classification, monitoring the state of agricultural crops by collection, processing, modification and analysis of monitoring information received from Russian and foreign spacecraft, creating cartographic thematic products (layers on an electronic map) across the region based on heterogeneous information integrated into a thematically oriented GIS. 


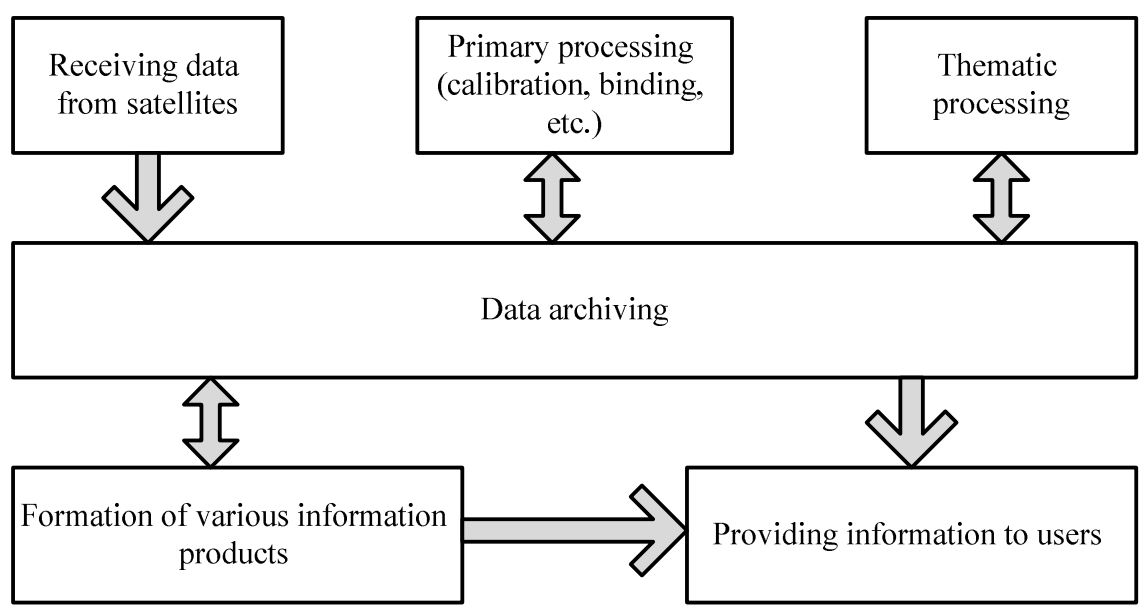

Fig. 5. The life cycle of processing and application of information.

The main tasks solved by the target agricultural monitoring system:

- monitoring the state of agricultural land (nature of land use, state of vegetation cover of agricultural land and its unauthorized or inappropriate use);

- assessment of projected damage from the effects of negative natural and man-made factors;

- monitoring and evaluation of agricultural activities (monitoring of individual stages of the agricultural cycle, monitoring of sowing and harvesting);

— inventory of agricultural land regulated by requirements for cadastral registration;

- predictive assessment of the impact of climatic and weather conditions on the main indicators of the effectiveness of the agricultural sector.

The target agricultural monitoring system also includes a module designed to increase the efficiency of obtaining timely and reliable information regarding the cultivation of drug-containing plants, preparing information in an aggregated, consistent and visual form, integrated processing of ERS data, ground-based observations and measurements, support for management decisions by the administration of the subject of Russia.

Special software for this module includes the following blocks:

— detection unit (ERS data processing), including modules for preliminary calculations of object parameters and thematic decryption of space information;

- GIS-technology unit, consisting of a module for displaying and analyzing the results of the detection system, as well as a module for presenting the results of work to the relevant specialized bodies.

The interface of the module considered above is presented in Fig. 6.

The result of the GIS technology considered is a thematic map with a layer of illegal vegetation, a layer of camouflage vegetation and attribute information.

The result of the GIS technology considered is a thematic map with a layer of illegal vegetation, a layer of camouflage vegetation and attribute information.

As part of the target agricultural monitoring system, it is advisable to have a set of workstations focused on the work of specialists in various fields, for example:

- the workstation of the operator of the agricultural department (department, regional ministry), providing input, storage and editing of geometric and attribute information on agricultural land plots, comprehensive analysis and planning of agricultural work and labor resources based on GIS, Web technologies and ERS data; 
- the workstation of the agronomist operator, designed for the distributed work of operators (agronomists) with information from a spatial database based on GIS technologies, and the use of ERS data.

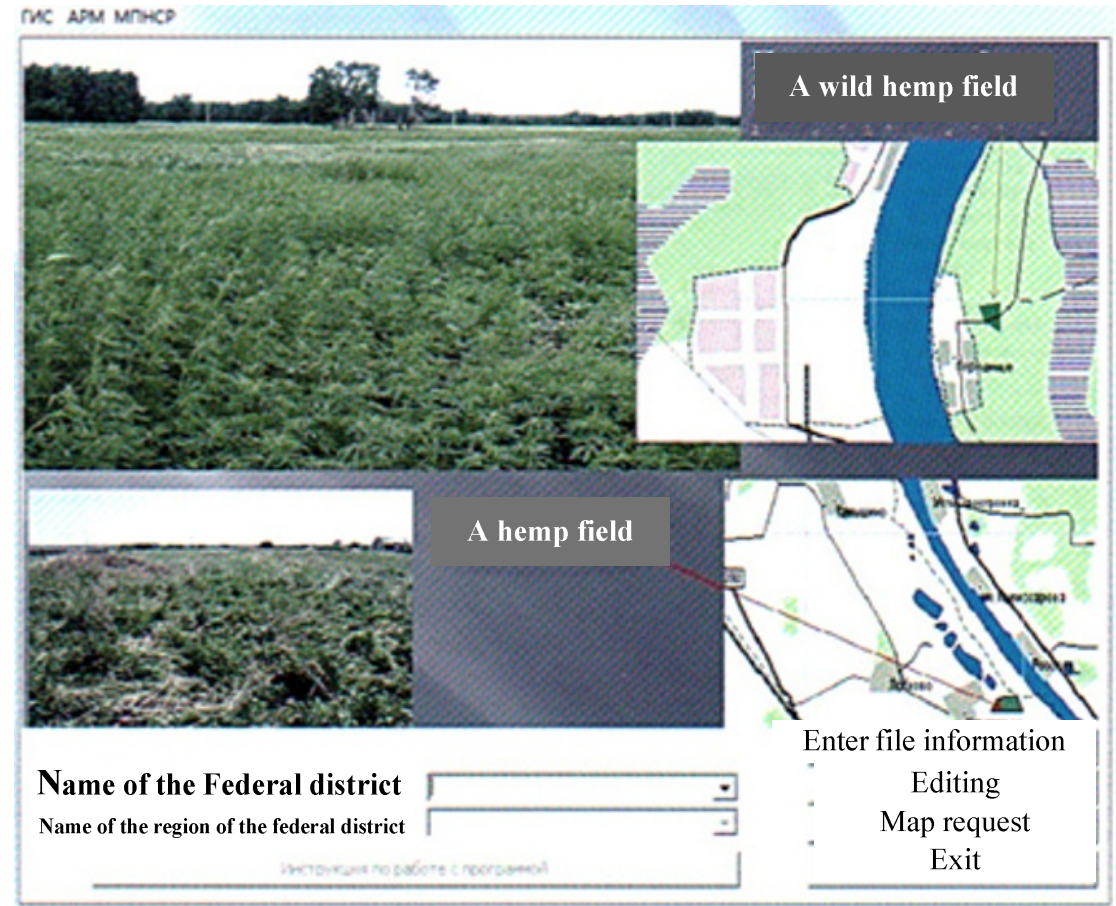

Fig. 6. The interface of illegal crop detection module.

ERS raster data is presented in TIFF format with a binding file (*.tfw), as well as GeoTiff.

The works within the framework of the presented project are underway on the basis of the layout of the viticulture situational center created at the Research Institute "Magarach" RAS, however, it is advisable to single out the following as the obtained or expected results:

1. The need to use geographical information technologies has been conceptually substantiated based on domestic results of space activities in monitoring agricultural territories of the regions of the South of Russia to ensure the sustainable development of viticulture;

2. The concept of a targeted program for the use of geographical information technologies based on domestic results of space activities in monitoring agricultural areas of the regions of the South of Russia has been developed;

3. The structure of a monitoring system for a large agricultural region has been developed, the tasks solved by this system have been identified, and experimental verification of the developed provisions on mock-ups created on the basis of the COSMOS national geographic information system has been carried out.

\section{Conclusion}

The purpose of this article was to develop proposals for the creation of a space monitoring system for grape agrocenoses in the region of southern Russia, aimed at ensuring 
sustainable development of viticulture. The basic principles, structure, purpose and tasks solved by the basic modules of this system have been substantiated. An experimental verification of the proposals formulated in the work has been carried out.

It should be noted that it is advisable to build a virtual environment on the basis of university data centers built on new principles, based on an innovative engineering solution that allows it to scale and connect new participants as needed, without requiring additional investment.

\section{Acknowledgments}

The reported study was funded by RFBR, project number 20-016-00220.

\section{References}

1. I.Yu. Grishin, R.R. Timirgaleeva, Materials of the III All-Russian Scientific Conference "Ecology and Space" named after academician K.Ya. Kondratyev (St. Petersburg, 2017)

2. I. Grishin, R.Timirgaleeva, CEUR Workshop Proceedings. 1. Ser. "Selected Papers of the 1st International Scientific Conference Convergent Cognitive Information Technologies, Convergent 2016 (2016)

3. V.G. Bezborodov, The State and Prospects of Using the Results of Space Activities in the Interests of Modernizing the Economy of the Russian Federation and Developing Its Regions (Entsitech, Moscow, 2014)

4. T.M. Komendanova, E.G. Imeskenova, Yu.V. Abgaldaev, Bulletin of the Buryat State Agricultural Academy 3(40), 63-68 (2015)

5. The passport of the national program "Digital Economy of the Russian Federation" (2018)

6. Q.B. Le, E. Nkonya, A. Mirzabaev, Economics of Land Degradation and Improvement - A Global Assessment for Sustainable Development (Springer International Publishing, 2016)

7. V.A. Rozhkov, I.O. Alyabina, V.M. Kolesnikova, E.N. Molchanov, V.S. Stolbovoy, S.A. Shoba, Soil Science 1, 3-6 (2010)

8. A.P. Glinushkin, V.N. Kudeyarov, M.S. Sokolov, V.E. Zinchenko, V.V. Chernenko, Biogeosystem Technique 5(2), 164-196 (2018)

9. V.I. Kiryushin, Agriculture 7, 3-6 (2013)

10. J. Braun Von, A. Mirzabaev, Baltic Region 8, 33-44 (2016) doi :10.5922/2079-85552016-3-3

11. M. Drosos, A. Piccolo, Land Degradation \& amp, amp Development 29(6), 1792-1805 (2018)

12. H. Elbasiouny, J. Soil. Sci. 58(4), 399-415 (2018)

13. A.S. Yakovlev, V.M. Gendugov, G.P. Glazunov, M.V. Evdokimova, E.A. Shulakova, Soil Science 8, 984-995 (2009)

14. F.N. Lisetskiy, E.I. Ergina, Soil Science 6, 643-657 (2010)

15. E.I. Ergina, S.G. Cherny, Scientiific notes. Tauride National University named after V.I. Vernadsky, Ser. Geography 24(63)-2.3, 67-72 (2011)

16. E.I. Ergina, Geopolitics and Ecogeodynamics of Regions 8(1-2), 62-72 (2012) 
17. E.V. Shein, I.M. Ryzhova, Mathematical Modeling in Soil Science ("IE Marakushev A. B.", Moscow, 2016)

18. I.M. Mikhailenko, V.N. Timoshin, Taurian Bulletin of Agrarian Science 1(13), 63-74 (2018)

19. A. Bonfante, F. Terribile, J. Bouma, SOIL 5, 1-14 (2019) https://doi.org/10.5194/soil5-1-2019

20. S.Yu. Blokhina, Bulletin of the Russian Agricultural Science 5 (2018)

21. I.S. Kozubenko, I.Yu. Savin, Bulletin of the Russian Agricultural Science 5, 9-11 (2017)

22. K.N. Kulik, A.V. Koshelev, Forestry Journal 3, 107-114 (2017)

23. A. Chervan', The Proceedings of the 10th International Soil Science Congress, Environment and Soil Resources Conservation (2018)

24. A.M. Melesse, Q. Weng, P.S.Thenkabail, G.B. Senay, Sensors 7(12), 3209-3241 (2007)

25. The CEOS database (2019) http://database.eohandbook.com/timeline/timeline.aspx

26. E.A. Lupyan, A.A. Mazurov, R.R. Nazirov, A.A. Proshin, E.V. Flitman, Yu.S. Krasheninnikova, Modern Problems of Remote Sensing of the Earth from Space 8(1), 26-43 (2011)

27. E.A. Lupyan, V.P. Savorsky, Yu.I. Shokin, A.I. Aleksanin, R.R. Nazirov, I.V. Nedoluzhko, O.Yu. Panova, Modern Problems of Remote Sensing of the Earth from Space 9(5), 21-44 (2012)

28. A.F. Sidko, I.Yu.Pugacheva, A.P. Shevyrnogov, Journal of Siberian Federal University, Engineering \& Technologies 2, 100-110 (2009)

29. K. Panigrahy, S. Ray, Journal of the Indian Society of Remote Sensing 37(2), 325-333 (2009)

30. S.B. Idso, R.D. Jackson, Jr.P.J. Pinter, M.S. Moran, R.J. Reginato, J.L. Hartfield, Agricultural Meteorology 24, 45-55 (1981)

31. S.J. Zwart, W.G.M. Bastiaanssen, Agricultural Water Management 69, 115-133 (2004)

32. J.W. Rouse, R.H. Haas, J.A. Schell, D.W. Deering, Monitoring vegetation systems in the Great Plains with ERTS. Third Earth Resources Technology Satellite-1 Symposium (NASA SP-351, Washington DC, 1973)

33. M. Hansen, R. Dubayah, R. Defries, International Journal of Remote Sensing 17, 1075 1081 (1996)

34. G.M. Foody, International Journal of Remote Sensing 17, 1317-1340 (1996)

35. G.M. Foody, International Journal of Remote Sensing 19, 2593-2599 (1998)

36. F. Van der Meer, International Journal of Remote Sensing 16, 3189-3194 (1995)

37. W.P. Kustas, M.C. Anderson, J.G. Alfieri, Bulletin of the American meteorological society 99(9), 1791-1812 (2018) doi: 10.1175/BAMS-D-16-0244.1

38. J. Rinza, D.A. Ramirez, J. Garcia, Potato Research 62(2), 109-122 (2019) doi: 10.1007/s11540-018-9400-5

39. A. Matese, S.F. Di Gennaro, Agriculture-BASEL 8(7), 116 (2018) doi: 10.3390/agriculture8070116

40. L. Padua, P. Marques, J. Hruska, T. Adao, Remote Sensing 10(12), 1907 (2018) doi: $10.3390 /$ rs 10121907 
41. M. Zovko, U. Zibrat, M. Knapic, Precision Agriculture 20(2), 335-347 (2019) doi: 10.1007/s11119-019-09640-2 